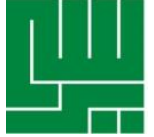

\section{KATA KUNCI} KEYWORDS

ABSTRAK

ABSTRACT

\title{
Kesejahteraan Psikologis Perempuan Anggota PKK
}

\author{
Psychological Well Being of Women Who Volunteered at PKK
}

\author{
Josephine Ondja, Olivia Hadiwirawan \\ Fakultas Psikologi Universitas Kristen Krida Wacana \\ Jl. Tanjung Duren Raya no. 4, Jakarta Barat \\ Josephine.2013fpsi050@civitas.ukrida.ac.id, Olivia.hadiwirawan@ukrida.ac.id
}

Kesejahteraan psikologi, pekerja sosial, perempuan

Psychological well-being, social worker, women

PKK (Pemberdayaan dan Kesejahteraan Keluarga) merupakan salah satu organisasi di Indonesia yang berupaya meningkatkan kesejahteraan masyarakat melalui pemberdayaan perempuan di masyarakat sekitar. Penelitian ini bertujuan menggambarkan kesejahteraan psikologis perempuan yang menjadi volunteer di PKK. Penelitian ini menggunakan strategi mixed-method sequential explanatory yang terdiri dari dua tahapan yaitu kuantitatif dan selanjutnya adalah kualitatif. Data kuantitatif didapatkan dari 78 anggota perempuan anggota PKK di Keluaran Tanjung Duren Utara, Jakarta dengan menggunakan skala Ryff's Short Version Scale of Psychological Well-Being yang sudah dimodifikasi. Hasil dari analisis kuantitatif yang telah dikategorisasikan menunjukkan bahwa kesejahteraan psikologis perempuan anggota PKK mayoritas berada pada kategori tinggi untuk dimensi autonomy, positive relations with other, personal growth, purpose in life, dan self-acceptance; kategori sedang untuk dimensi environmental mastery. Tiga orang perempuan yang termasuk ke dalam kategori tinggi pada dimensi purpose in life dan self-acceptance kemudian diwawancara lebih lanjut untuk mengeksplorasi gambaran kesejahteraan psikologisnya. Dari hasil analisa kualitatif ditemukan tema utama pada dimensi purpose in life adalah perempuan mengabdikan hidup mereka untuk keluarga dan masyarakat. Sedangkan tema utama yang muncul pada dimensi selfacceptance adalah perempuan yang ikhlas menjalani peran mereka. PKK kemudian dapat menjadi sarana bagi para perempuan untuk mencapai dan memertahankan

PKK (Empowerment and Family) is one of organization in Indonesia that aim to increase community's welfare through empowering women in community. This study was intended to describe psychological wellbeing of women who volunteered in PKK. This study used mixed methods sequential explanatory strategy, consisted of two phases, quantitative followed by qualitative. Quantitative data were collected from 78 women members of PKK in Tanjung Duren Utara SubDistrict, Jakarta by using modified Ryff's Short Version Scale of Psychological Well-being. The result from quantitative analysis was categorized and showed psychological well-being of member PKK are high category for autonomy, self-acceptance, purpose in life, positive relations with others, and personal growth dimension; moderate category for environmental mastery dimension. Three women who 
have high score categorization in purpose in life and self-acceptance dimension were selected and interviewed to describe the psychological well being. In qualitative analysis, the major themes emerged for purpose in life dimension was women devoted their life for family and society. Themes emerged for self-acceptance dimension was women who sincere (ikhlas) in doing their role in community. PKK could emerge as a vessel for women to achieve and maintain their psychological well being.

\section{PENDAHULUAN}

Kesejahteraan dan kebahagiaan merupakan hal yang ingin dicapai semua orang di dunia (Diener, Oishi \& Lucas, 2003). Dua pandangan besar mengenai kesejahteraan salah satunya adalah pandangan eudaimonik atau kesejahteraan psikologis (psychological well-being). Sejahtera secara eudaimonik bukan berarti individu terus merasa senang dan tidak merasakan afek negatif. Kesejahteraan psikologis berarti individu mampu menyadari potensi dirinya dan mengaktualisasikan diri (Ryff, 2014). Ryff (2014) mengemukakan bahwa kesejahteraan psikologis merupakan pencapaian tertinggi dalam kehidupan manusia.

Berbagai penelitian telah mengungkapkan dampak positif kesejahteraan psikologis terhadap individu, organisasi, dan masyarakat (Ruini \& Ryff, 2016; Ryff, 2014; Zizek, Treven \& Cancer, 2015). Bagi individu, kesejahteraan psikologis memiliki dampak positif bagi kesehatan baik secara fisik maupun mental. Dalam aspek biologis, individu yang sejahtera secara psikologis beresiko lebih rendah mengidap penyakit metabolis kronis, penyakit degeneratif, gangguan kognitif, komordibitas. Seseorang yang memiliki kesejahteraan psikologis yang tinggi cenderung dapat hidup lebih lama (Ruini \& Ryff, 2016). Bagi organisasi, kesejahteraan psikologis berdampak kepada kualitas dan kuantitas pekerja yang secara konsekuen juga berdampak kepada organisasi (Zizek, Treven, \& Cancer, 2015). Kesejahteraan psikologis merupakan motivasi penggerak utama bagi individu di dalam organisasi sehingga orang yang memiliki kesejahteraan psikologis yang tinggi bekerja lebih baik di dalam pekerjaannya (Robertson \& Tinline dalam Zizek et al., 2015).

Ryff (2013) menyatakan salah satu faktor yang berkontribusi terhadap kesejahteraan psikologis adalah pekerjaan dan keterlibatan dalam kegiatan volunteering. Penelitian menunjukkan volunteering secara formal dapat meningkatkan kesejahteraan psikologis (Choi \& Kim, 2011; Greenfield \& Marks, 2004; Son \& Wilson, 2012). Kegiatan volunteering secara formal terbukti menjadi faktor protektif bagi individu dalam menghadapi kehilangan peran pada saat usia lanjut (Greenfield \& Marks, 2004; Thoits \& Hewitt, 2001 dalam Ho, 2015). Partisipasi dalam kegiatan seperti volunteering dapat menjaga hubungan baik dengan orang lain, meningkatkan self-affirmation, mengurangi stres dan kecemasan, membantu menyadari potensi individu, meningkatkan kepuasan hidup, dan memberikan individu akses yang lebih banyak untuk dukungan sosial, menyadari makna hidup sehingga dapat meningkatkan kesejahteraan psikologis (Greenfield \& Marks, 2004; HaskiLeventhal, 2009 dalam Ho, 2015). Akan tetapi, jika kegiatan volunteering ini dilakukan karena terpaksa maka tidak akan ada pengaruhnya terhadap peningkatan kesejahteraan psikologis. Lindfors (dalam Ryff, 2013) menemukan bahwa wanita yang bekerja tidak dibayar memiliki self acceptance dan environmental mastery yang lebih rendah. Gerakan PKK (Pemberdayaan dan 
Kesejahteraan Keluarga) adalah salah satu organisasi di Indonesia yang berupaya meningkatkan kesejahteraan masyarakat dengan memberdayakan perempuan sebagai agen untuk meningkatkan kesejahteraan masyarakat dari unit terkecil yaitu keluarga. Anggota PKK biasanya adalah perempuan dengan gagasan bahwa perempuan adalah agen penting dalam peningkatan kesejahteraan di dalam keluarga dan masyarakat (Rantung, Mandey \& Londa, 2014). PKK menjadi salah satu mitra pemerintah dalam meningkatkan kesejahteraan masyarakat lewat pemberdayaan perempuan.

PKK menyasar kesejahteraan keluarga karena keluarga merupakan unit terkecil yang akan berpengaruh besar terhadap pembangunan negara. Untuk dapat mencapai seluruh unit masyarakat, PKK hadir di berbagai lapisan tingkat pemerintahan mulai dari tingkat RW (Rukun Warga), kelurahan, kecamatan, kota, provinsi, hingga tingkat pusat. PKK diketuai oleh istri kepala pemerintahan di setiap tingkatan (RW hingga pusat) dan beranggotakan masyarakat yang secara sukarela berpartisipasi. Meskipun keanggotaan PKK diperbolehkan diikuti oleh laki-laki, mayoritas anggota PKK adalah perempuan.

Berdasarkan wawancara yang dilakukan kepada anggota PKK RW di Kelurahan TDU Jakarta Barat, programprogram yang secara aktif dilaksanakan di PKK Kelurahan TDU di setiap RW antara lain Posyandu, Posbindu, PAUD, PIK dan penyuluhan seputar KB, Pemberantasan Sarang Nyamuk, arisan, pengajian, dan sebagainya. PKK terutama di tingkat RW dapat dikatakan sebagai ujung tombak pemerintah dalam meningkatkan kesejahteraan masyarakat karena PKK di tingkat RW bertugas untuk terjun langsung ke rumah-rumah warga dan masyarakat. Anggota PKK di DKI Jakarta sebetulnya diberikan upah tergantung dari tugas dan pekerjaan mereka akan tetapi upah tersebut sebetulnya juga menurut mereka sedikit dan seringkali upah tersebut juga tidak digunakan untuk diri mereka sendiri melainkan untuk membeli seragam, mencetak foto untuk dikirimkan ke kelurahan, dan sebagainya. Anggota PKK di Kelurahan TDU mayoritas berusia paruh baya hingga lansia. Beberapa anggota yang diwawancarai mengaku aktif menjadi anggota PKK untuk mengisi waktu luang karena mereka sudah tidak bekerja dan anak serta cucu sudah beranjak dewasa. Alasan lain mengikuti PKK adalah sebagai sarana untuk bersosialisasi dengan anggota PKK lainnya.

Purnomo \& Hadiwirawan (2017) melakukan eksplorasi kesejahteraan subjektif anggota PKK berdasarkan frekuensi partisipasi dalam kegiatan PKK. PKK membantu para anggotanya merasa aktif dan produktif, terutama karena sebagian besar dari anggotanya merupakan pensiunan dan memiliki anak yang sudah berkeluarga dan bekerja. Kesejahteraan subjektif mengacu pada kondisi kesejahteraan individu berdasarkan penilaian kognitif dan afektif (Diener, 2000). Hasil penelitian menunjukkan bahwa para anggota PKK tersebut memiliki tingkat kepuasaan hidup dan kebahagiaan yang tinggi sebagai pengukuran kesejahteraan subjektif. Meski demikian, kesejahteraan subjektif tidak berhubungan dengan tingkat partisipasi kegiatan.

Ryff (2013b) mengemukakan bahwa kesejahteraan psikologis adalah sejauh mana seorang individu memiliki tujuan dalam hidupnya, apakah mereka menyadari potensi yang dimiliki, kualitas hubungannya dengan orang lain, dan sejauh mana mereka merasa bertanggung jawab dengan hidupnya sendiri. Kesejahteraan psikologis merupakan gambaran kesehatan psikologis individu berdasarkan pemenuhan fungsi psikologis positif (Ryff, 2013b). Kesejahteraan psikologis didasarkan pada pandangan eudaimonik yang memandang 
kesejahteraan tidak hanya sebatas perasaan nyaman dan senang semata (hedonik), melainkan individu dapat mengenal dirinya dan hidup sesuai dengan tujuan hidup masing-masing.

Ryff (2014) mengemukakan bahwa kesejahteraan psikologis ditandai oleh adanya enam dimensi antara lain:

- Penerimaan diri (self-acceptance) : individu mengakui dan menerima berbagai aspek dalam dirinya baik kelebihan maupun kekurangan, dapat mengakui dan menerima masa lalu.

- Hubungan positif dengan orang lain (positive relations with others) : individu memiliki hubungan yang dekat, hangat, dan saling percaya dengan orang lain, mampu berempati dan peduli terhadap lingkungannya.

- Kemandirian (autonomy): individu mampu mandiri dalam mengambil keputusan, mampu berperilaku bebas tanpa tekanan dari sosial, menentukan standar pribadi dalam mengevaluasi diri.

- Penguasaan terhadap lingkungan (environmental mastery): individu mampu mengelola tanggung jawab, berpartisipasi dalam lingkungannya dan meningkatkan lingkungan lewat aktivitas fisik maupun mental secara kreatif.

- Tujuan hidup (purpose in life): individu menyadari adanya makna dan tujuan dalam kehidupannya.

- Perkembangan pribadi (personal growth): individu menyadari bahwa kehidupan merupakan proses belajar terus menerus dan memiliki keinginan untuk berkembang, terbuka terhadap pengalaman baru.

Keterlibatan perempuan dalam kegiatan PKK secara sukarela berarti individu terlibat dalam kegiatan volunteering. Individu yang berpartisipasi dalam kegiatan volunteer, dapat menemukan kembali tujuan dalam hidup (purpose in life) (Greenfield \& Marks, 2004). Partisipasi dalam aktivitas keagamaan juga terbukti meningkatkan semua aspek dari PWB terutama hubungan positif dengan orang lain (positive relations with others) pada wanita (Greenfield, 2009). Dukungan sosial yang didapatkan juga mempengaruhi PWB dalam aspek hubungan positif dengan orang lain (positive relationship with others) (Nezlek \& Allen, 2006). Volunteer di PKK mayoritas berusia paruh baya hingga lansia. Pada usia itu individu berada pada tahapan tugas perkembangan generativity dimana individu merasa butuh untuk membantu generasi selanjutnya. Generativity dapat dicapai salah satunya lewat aktif dalam kegiatan volunteering atau keterlibatan di masyarakat (An \& Cooney, 2006). Dengan terlibat dalam kegiatan volunteering di lingkungan tempat tinggalnya, individu memperoleh hubungan sosial dengan tetangganya (Desiningrum, 2010). Tetangga sekitar dapat menjadi sumber utama dari dukungan dan makna hidup bagi di usia dewasa (Gardner, 2011). Dukungan yang diterima dari tetangga juga dapat mempertahankan kesejahteraan psikologis individu agar tetap tinggi (Greenfield \& Reyes, 2014). Berdasarkan penjelasan tersebut, peneliti melakukan penelitian dan mencari tahu "Bagaimana kesejahteraan psikologis perempuan yang mengikuti PKK?"

\section{METODE PENELITIAN}

Penelitian ini menggunakan mixedmethod dengan sequential explanatory strategy, yaitu penelitian dengan strategi pengumpulan data dan analisis data kuantitatif terlebih dahulu kemudian diikuti dengan pengumpulan data dan analisa kualitatif yang dibangun dari hasil peneltian kuantitatif (Creswell, 2012). Penelitian kuantitatif dilakukan untuk menggambarkan tingkat kesejahteraan psikologis anggota PKK, sementara penelitian kualitatif dilakukan untuk memahami lebih dalam mengenai gambaran kesejahteraan psikologis pada dimensi tertentu serta mengklarifikasi 
hasil dari penelitian kuantitatif.

\section{Proses Tahapan Kuantitatif}

Subjek pada tahapan kuantitatif adalah perempuan anggota PKK yang masih aktif mengikuti kegiatan PKK di Kelurahan TDU. Teknik pengambilan sampel yang digunakan adalah nonprobability sampling dengan menggunakan sampel jenuh. Peneliti menggunakan teknik sampling ini karena jumlah populasi yang ingin diteliti relatif kecil yaitu 98 orang anggota PKK yang masih aktif mengikuti kegiatan PKK di Kelurahan TDU. Dari 98 orang anggota PKK yang terdaftar di kelurahan, hanya 78 orang yang dapat ditemui dalam kegiatan PKK. Partisipan mayoritas berusia 50-69 tahun (59\%), sudah menikah (62,8\%), merupakan ibu rumah tangga $(84,6 \%)$, dan pendidikan terakhirnya SMA $(51,3 \%)$.

Skala yang digunakan menggunakan skala Likert Ryff's Psychological Well Being Scale (Ryff \& Keyes, 1995). Terdapat dua jenis skala dari Ryff's Psychological Well Being Scale yaitu versi 48 aitem dan versi 18 aitem. Peneliti memutuskan untuk menggunakan skala berjumlah 18 aitem dengan dasar pertimbangan tingkat pendidikan anggota PKK dan usia anggota PKK yang sebagian besar merupakan lansia. Skala disusun dalam enam respon jawaban dari Sangat Tidak Setuju hingga Sangat Setuju. Skala berupa 18 pernyataan tertutup yang dikembangkan dari 6 dimensi PWB. Setiap dimensi diukur oleh 3 pernyataan yang terbagi menjadi pernyataan favorable dan pernyataan unfavorable. Peneliti melakukan penerjemahan skala dari bahasa Inggris ke bahasa Indonesia, kemudian menerjemahkannya kembali ke bahasa Inggris untuk melihat konsistensi dalam makna dan konten. Selain itu peneliti juga melakukan uji keterbacaan terhadap tiga orang wanita usia paruh baya hingga lansia serta memastikan agar setiap aitem dapat dimengerti oleh responden.
Berdasarkan uji validitas didapatkan nilai validitas aitem yang dilihat dari corrected item total correlation berkisar antara 0,010 hingga 0,609. Terdapat delapan aitem yang tidak valid $(r<0,3)$ dari total 18 aitem sehingga aitem-aitem yang tidak valid dieliminasi. Setelah aitem dengan validitas rendah dibuang, tersisa 10 aitem. Hasil uji reliabilitas didapatkan nilai koefisien $\alpha=0,840$.

\section{Proses Tahapan Kualitatif}

Pada tahapan kualitatif peneliti memilih dua dimensi untuk digali lebih mendalam. Peneliti memilih dimensi purpose in life dan self-acceptance. Dimensi purpose in life dipilih karena pada dimensi ini $80 \%$ partisipan berada pada kategori tinggi. Dimensi self-acceptance dipilih karena pada saat menyebarkan skala pada saat menyebarkan skala di salah satu RW, ada partisipan yang memberikan respon bahwa individu yang menyukai kepribadiannya sendiri berarti individu tersebut sombong dan pernyataan tersebut disetujui oleh beberapa partisipan lain yang mengikuti kegiatan di RW tersebut.

Terdapat delapan orang yang memiliki nilai tertinggi pada dimensi selfacceptance dan purpose in life. Peneliti kemudian mempertimbangkan lamanya partisipan-partisipan tersebut aktif di PKK dan kegiatan apa saja yang diikuti di PKK. Dari delapan orang terdapat empat orang yang hanya mengikuti satu kegiatan saja di PKK ataupun baru aktif mengikuti kegiatan di PKK kurang dari dua tahun sehingga partisipan yang tersisa adalah empat orang. Peneliti menghubungi keempat orang tersebut dan satu orang yang pada saat peneliti menyebarkan skala kuantitatif mengatakan bahwa menyukai kepribadian berarti sombong. Dari lima orang yang dihubungi, tiga orang bersedia menjadi partisipan penelitian. Tiga orang perempuan yang termasuk ke dalam kategori tinggi pada dimensi purpose in life dan self-acceptance kemudian diwawancara lebih lanjut untuk mengeksplorasi gambaran kesejahteraan 
psikologisnya. Setiap partisipan diwawancarai selama kurang lebih 30-45 menit. Wawancara dilakukan dengan pedoman umum. Peneliti dapat menyesuaikan pertanyaan dengan konteks aktual saat wawancara berlangsung (Poerwandari, 2013). Peneliti membuat pedoman wawancara berdasarkan aitem pada tahapan penelitian kuantitatif. Hal ini dilakukan karena tujuan dari tahapan penelitian kualitatif ini adalah untuk memahami lebih dalam mengenai gambaran kesejahteraan psikologis pada dimensi tertentu serta mengklarifikasi hasil dari penelitian kuantitatif. Pertanyaan yang ditanyakan peneliti antara lain adalah: kegiatan sehari-hari subjek, kegiatan apa saja yang diikuti di PKK, suka duka dalam menjadi anggota PKK, apa tujuan hidup partisipan, kepribadian seperti apa yang dimiliki partisipan, dan apakah partisipan menyukai kepribadian mereka.

\section{Hasil Penelitian Kuantitatif}

Peneliti melakukan kategorisasi untuk mengetahui tinggi rendahnya nilai subjek pada skala RPWB dan setiap dimensinya Kategorisasi dibagi menjadi tiga kategori yaitu tinggi, sedang, dan rendah berdasarkan distribusi kurva normal dengan menggunakan rumus dari Azwar (2015). Tabel 1 memuat perhitungan norma hipotetik untuk total kesejahteraan psikologis dan dimensi environmental mastery, self-acceptance, positive relations with others, purpose in life, autonomy, dan personal growth. Sementara Tabel 2 memuat perhitungan norma hipotetik untuk total kesejahteraan psikologis dan dimensi environmental mastery, self-acceptance, positive relations with others, purpose in life, autonomy, dan personal growth.

\section{ANALISIS \& HASIL}

Tabel 1

Perhitungan Norma Hipotetik Total Kesejahteraan Psikologis

\begin{tabular}{lcccc}
\hline Kategorisasi & Rumus & Hasil & Frekuensi & Presentase (\%) \\
\hline Tinggi & $\mathrm{X} \geq(\mu+1 \sigma)$ & $\mathrm{X} \geq 43.3$ & 60 & $77 \%$ \\
\hline Sedang & $(\mu-1 \sigma) \leq \mathrm{X}<(\mu+1 \sigma)$ & $26.7 \leq \mathrm{X}<43.3$ & 17 & $22 \%$ \\
\hline Rendah & $\mathrm{X}<(\mu-1 \sigma)$ & $\mathrm{X}<26.7$ & 1 & $1 \%$ \\
\hline Total & & & $\mathbf{7 8}$ & $\mathbf{1 0 0 \%}$ \\
\hline
\end{tabular}

Tabel 2

Kategorisasi tiap Dimensi Kesejahteraan Psikologi

\begin{tabular}{ccccccc}
\hline Dimensi & \multicolumn{2}{c}{ Rendah } & \multicolumn{2}{c}{ Sedang } & \multicolumn{2}{c}{ Tinggi } \\
\cline { 2 - 8 } & $\mathbf{f}$ & $\mathbf{\%}$ & $\mathbf{f}$ & $\mathbf{\%}$ & $\mathbf{f}$ & $\mathbf{\%}$ \\
\hline Kesejahteraan Psikologis & 1 & 1 & 17 & 22 & 60 & 77 \\
\hline Environmental Mastery & 2 & 3 & 45 & 58 & 31 & 40 \\
\hline Personal Growth & 1 & 1 & 26 & 35 & 51 & 64 \\
\hline Self-Acceptance & 7 & 9 & 10 & 13 & 61 & 78 \\
\hline Autonomy & 4 & 5 & 19 & 24 & 55 & 71 \\
\hline Positive Relations with Others & 6 & 8 & 10 & 13 & 62 & 80 \\
\hline Purpose in Life & 2 & 3 & 5 & 6 & 71 & 91 \\
\hline
\end{tabular}

Kesejahteraan psikologis anggota PKK kelurahan TDU mayoritas $(\mathrm{M}=45,98 ; \quad \mathrm{SD}=5,61)$ berada pada kategori tinggi dilihat dari sebaran normal. Dalam dimensi self-acceptance $(\mathrm{M}=4,68 ; \mathrm{SD}=1,06)$, positive relations with others $(\mathrm{M}=4,71 ; \mathrm{SD}=1,01)$, purpose in life $(\mathrm{M}=5,14 ; \mathrm{SD}=0,85)$, autonomy $(\mathrm{M}=9,08 ; \mathrm{SD}=1,81)$, dan personal growth $(\mathrm{M}=9,12 ; \quad \mathrm{SD}=1,84) \quad$ juga terlihat mayoritas anggota PKK kelurahan TDU berada pada kategori tinggi. Akan tetapi dalam dimensi environmental mastery 
mayoritas berada pada kategori sedang $(\mathrm{M}=13,27 ; \mathrm{SD}=1,88)$.

\section{Hasil Penelitian Kualitatif}

Subjek dalam penelitian ini terdiri dari tiga orang yang merupakan perempuan anggota PKK kelurahan TDU. Kisaran usia partisipan adalah 48 hingga 62 tahun. Subjek C dan G merupakan guru PAUD, sementara subjek $\mathrm{T}$ merupakan Pekerja Sosial Masyarakat. Range lama berpartisipasi dalam kegiatan PKK adalah 3 hingga 30 tahun.

Bagi subjek $\mathrm{C}$, tujuan hidup merupakan cita-cita, keinginan. Bagi subjek C, untuk mencapai tujuan yang penting adalah usaha dan program untuk mencapai tujuan tersebut, untuk hasil merupakan urusan nanti. Subjek C berpendapat bahwa sebagai manusia kita harus mempunyai tujuan hidup. Bagi subjek $\mathrm{C}$, tujuan hidupnya adalah mengabdi di masyarakat. Akan tetapi, menurut subjek $\mathrm{C}$ tujuan hidup prioritasnya adalah kesejahteraan keluarganya terlebih dahulu. Setelah keluarganya sejahtera, ia baru menyejahterakan masyarakat. Partisipan mengabdi kepada masyarakat dengan berbagi pengetahuan dan memberikan penyuluhan.

Subjek T menyatakan tujuan hidupnya adalah berbakti untuk masyarakat dan berguna untuk sekitarnya baik keluarga, masyarakat, dan lingkungannya. Bagi $\mathrm{T}$ tujuan utamanya adalah berbakti bagi keluarga, setelah itu ke lingkungan dan masyarakat. $\mathrm{T}$ menyatakan bahwa karena kita hidup di masyarakat, oleh karena itu kita harus ikut membantu lingkungan di sekitar kita.

Tabel 3

Gambaran Umum Subjek Kualitatif

\begin{tabular}{|c|c|c|c|c|c|}
\hline $\begin{array}{l}\text { Inisial } \\
\text { Subjek }\end{array}$ & Usia & $\begin{array}{c}\text { Status } \\
\text { Pernikahan }\end{array}$ & $\begin{array}{c}\text { Pendidikan } \\
\text { Terakhir }\end{array}$ & $\begin{array}{c}\text { Kegiatan yang diikuti } \\
\text { di PKK }\end{array}$ & Lama Berpartisipasi \\
\hline $\mathrm{C}$ & 62 & Menikah & SMA & $\begin{array}{l}\text { - } \quad \text { PAUD } \\
\text { - } \text { arisan, } \\
\text { - } \text { pengajian, } \\
\text { - } \quad \text { Kader } \\
\text { Pemberantasan Sarang } \\
\text { Nyamuk (PSN) } \\
\text { - Posbindu } \\
\end{array}$ & kurang lebih 15 tahun \\
\hline $\mathrm{T}$ & 57 & Menikah & SMA & $\begin{array}{l}\text { - } \text { arisan, } \\
\text { - pengajian } \\
\text { - Pekerja Sosial } \\
\text { Masyarakat }\end{array}$ & kurang lebih 30 tahun \\
\hline $\mathrm{G}$ & 48 & Menikah & $\begin{array}{l}\text { S1- Teknik } \\
\text { Lingkungan }\end{array}$ & $\begin{array}{l}\text { - PAUD } \\
\text { - arisan }\end{array}$ & 3.5 tahun \\
\hline
\end{tabular}

Subjek $\mathrm{T}$ mewujudkan pengabdiannya pada lingkungannya lewat membagikan ilmu yang ia dapatkan dari pelatihan yang diikuti di PKK. Pelatihan yang diikuti subjek antara lain pelatihan mengenai kesehatan, narkoba, pendidikan, keluarga berencana, BPJS, dan lain-lain. Subjek T mengaku bahwa pelatihan yang ia dapatkan direfleksikan sehingga ia sadar bahwa banyak yang lebih berkesulitan baginya. Selain membagikan ilmu yang ia dapatkan dari pelatihan PKK ataupun Pekerja Sosial Masyarakat (PSM), ia sebulan sekali mengikuti pelatihan rutin untuk mendiskusikan masalah sosialisasi, serta $\mathrm{T}$ juga membantu tetangga, anak yatim, lansia yang membutuhkan di lingkungannya. Bagi $\mathrm{T}$, ia merasa tidak dapat membantu orang-orang yang kurang mampu dengan materi, oleh karena itu ia membantu dengan tenaganya. $\mathrm{T}$ mengaku senang berbagi 
lewat tenaganya.

Subjek G mengatakan bahwa semua orang pasti harus punya tujuan hidup. Bagi $G$ tujuan hidup sudah diatur berdasarkan agama. G menjelaskan karena diatur oleh agama maka tujuan hidup kita adalah untuk Allah dengan cara berbagi untuk orang lain, membahagiakan orang lain, berguna untuk orang lain. Menurut $G$ hal ini karena kita tidak hidup sendirian. G mengatakan kalau diri sendiri sudah tercukupi, individu harus berbagi, berbagi apapun yang ia punya seperti ilmu. G mengatakan dengan membahagiakan orang lain kita juga dengan sendirinya akan bahagia. Selain itu tujuan hidup bagi $\mathrm{G}$ adalah menjadi lebih baik.

Purpose in life berarti individu yang percaya mengenai adanya tujuan, makna dan arah dalam hidupnya. Berdasarkan hasil analisa, ketiga partisipan menyatakan bahwa semua orang harus memiliki tujuan hidup. Bagi partisipan G, tujuan hidupnya sudah diatur dalam agama, dimana tujuan hidupnya adalah menjadi wanita muslimah dan berguna bagi orang lain. Secara keseluruhan ketiga subjek menjelaskan bahwa tujuan hidup mereka adalah untuk mengabdi di masyarakat. Akan tetapi ketiga partisipan menyatakan bahwa sebelum menyejahterakan masyarakat, tujuan utama mereka adalah untuk keluarga mereka sendiri terlebih dahulu.

Subjek C menganggap kepribadian yang menilai adalah orang lain, bukan dirinya sendiri meskipun menurut $\mathrm{C}$ ia menyukai kepribadiannya. Subjek $\mathrm{C}$ juga menganggap sifat buruk masih merupakan hal yang manusiawi. Subjek T menceritakan bahwa ia senang jika dapat membantu orang, ia menceritakan pengalamannya membantu merawat lansia, kunjungan ke panti asuhan dan ia merasa tergerak hatinya melihat anakanak disana, dan pengalamanpengalaman membantu orang-orang lainnya. T mengaku bahwa memang ia sepertinya sudah berjiwa sosial sehingga terkadang ia tidak mencari uang ketika beraktivitas di PKK. Bahkan T mengatakan terkadang ia harus mengeluarkan uang dari kocek sendiri.

Tema yang muncul dari $T$ mengenai self-acceptance adalah menerima. Dari hasil wawancara $\mathrm{T}$ mengatakan gaji di PKK tidak seperti gaji yang rutin, pada saat ia berkeliling ia sering merasa lelah dan haus, terkadang malah ia harus mengeluarkan uang sendiri, tetapi ia menerima karena itu sudah tugas dari PKK.

Bagi $G$ individu harus menyukai kepribadian kita, tetapi kita tidak boleh sombong dan memamerkan kelebihan. Menurut G, orang yang tidak menyukai kepribadiannya berarti tidak punya prinsip, dan hanya menjadi followers. G menyebutkan contoh kepribadian yaitu pintar, percaya diri, sehingga hal-hal itu tidak perlu dipamerkan kepada orang lain. G memandang kepribadian sebagai pemberian dari Allah sehingga sebagai manusia kita harus menyukainya. Berdasarkan analisis, tema yang sering sekali muncul pada $G$ adalah ikhlas. Terdapat 18 kali G menjelaskan mengenai tema ikhlas. Bagi $\mathrm{G}$, keikhlasan adalah menerima dan mensyukuri apa yang ada, serta mensyukuri apa yang kita punya. $G$ menjelaskan terkadang dalam hidup kita tidak selalu mendapatkan apa yang kita inginkan. $\mathrm{G}$ menceritakan mengenai pengalamannya yang harus memilih antara berkarir atau memiliki anak. Pada saat itu ia memutuskan meninggalkan karirnya dan berhenti bekerja agar memiliki anak. Akan tetapi ia tidak langsung mendapatkan anak ketika ia memutuskan berhenti bekerja. Akhirnya ia membebaskan pikirannya dan mengikhlaskan kalau apa yang ia inginkan belum tentu sesuai dengan kenyataan yang ia dapatkan. Begitu G mengikhlaskan ternyata ia malah hamil. Bentuk keikhlasan yang dilakukan $\mathrm{G}$ antara lain positive thinking, 'dibawa happy', tidak membatasi apa yang kita suka dan apa yang tidak disukai, 'ambil 
pahalanya aja', dan menganggap rejeki di tangan Tuhan dan sudah ada yang mengatur sehingga yang perlu dilakukan hanyalah berusaha.

Self-acceptance berarti individu mampu menerima semua aspek dalam dirinya yang baik positif dan negatif, masa lalu dan sekarang. Penerimaan diri pada partisipan $\mathrm{G}$ digambarkan dengan kata ikhlas. $G$ yang awalnya sudah menempuh pendidikan yang cukup tinggi dan bekarir harus memutuskan untuk berhenti kerja demi memiliki anak. Setelah ia berhenti bekerja ia masih juga belum dikaruniai anak meskipun ia sudah berusaha dan berkonsultasi ke beberapa dokter. Akhirnya ia berusaha tidak terlalu memikirkan hal tersebut dan mengikhlaskannya. Pada akhirnya ia pun memiliki dua orang anak. G juga ikhlas menerima pekerjaannya sekarang sebagai guru PAUD yang bidangnya jauh berbeda dengan pendidikan yang ia tempuh. Penerimaan diri pada partisipan $T$ digambarkan dengan menerima. $\mathrm{T}$ menerima bahwa sebagai anggota PKK dan PSM memang tugasnya untuk terjun ke masyarakat meskipun gajinya kecil dan tidak rutin, terkadang ia malah harus mengeluarkan uangnya sendiri, lelah, dan haus dan ia tidak memikirkan hal itu. Partisipan $\mathrm{C}$ memandang sifat-sifat buruk yang ia punyai sebagai hal yang manusiawi. Partisipan G memandang kepribadian sebagai pemberian dari Allah yang harus kita terima.

\section{DISKUSI}

Penelitian ini menemukan bahwa kesejahteraan psikologis perempuan anggota PKK di kelurahan TDU tergolong tinggi. Kesejahteraan psikologis dinilai dari enam dimensi yaitu autonomy, self-acceptance, environmental mastery, positive relations with other, purpose in life, dan personal growth. Individu dengan kesejahteraan psikologis yang tinggi berarti individu mampu (1) menolak tekanan sosial untuk berpikir dan berperilaku dalam cara tertentu, mengevaluasi dirinya sendiri dengan standar pribadi, (2) mampu mengakui dan menerima berbagai aspek dari dirinya, termasuk sifat yang baik maupun yang buruk, (3) mampu memilih atau mengelola lingkungan sehingga sesuai dengan kebutuhan pribadi dan nilai individu, (4) memiliki tujuan dalam hidup, (5) memiliki hubungan yang dekat, memuaskan, dan saling percaya dengan orang lain, peduli mengenai kesejahteraan orang lain, dan (6) terbuka terhadap pengalaman baru (Ryff, 2014).

Pada setiap dimensi, secara keseluruhan hanya dimensi environmental mastery yang berada dalam kategori sedang, sedangkan dimensi lainnya berada pada kategori tinggi. Hasil penelitian kuantitatif menunjukkan bahwa partisipan masih agak merasa mengalami kesulitan dalam mengatur urusan sehari-hari, merasa tidak mampu untuk mengubah atau meningkatkan lingkungannya. Hal ini terlihat dari jawaban partisipan pada aitem nomor empat yaitu "terkadang saya lelah dengan tuntutan hidup sehari-hari" dimana mayoritas partisipan $(n=32)$ menjawab setuju dengan pernyataan ini. Mayoritas partisipan merupakan ibu rumah tangga dan merupakan kader PKK sehingga selain menyandang tanggungjawab di rumah mereka juga memiliki tanggungjawab sebagai kader di PKK. Hal ini tentunya menyebabkan mereka memiliki tugas dan tanggungjawab yang cukup banyak. Selain itu, kegiatan PKK dengan bayaran yang rendah juga dapat menyebabkan rendahnya environmental mastery. Hal ini didukung dengan penelitian Lindfors, Berntsson, Lundberg (dalam Ryff, 2013) mengenai hubungan antara pekerjaan dengan bayaran rendah atau tidak dibayar dengan kesejahteraan psikologis, dimana ada perbedaan hasil antara pria dan wanita. Bagi wanita, pekerjaan dengan bayaran rendah atau tidak dibayar berkorelasi dengan self-acceptance dan environmental mastery yang rendah. 
Hasil penelitian ini berbeda dengan penelitian Kertamuda dan Syamsu (2014) mengenai gambaran kesejahteraan psikologis ibu yang menjadi anggota PKK yang menemukan bahwa kesejahteraan psikologis ibu yang menjadi anggota PKK berada pada kategori sedang. Pada penelitian Kertamuda dan Syamsu (2014) jika dilihat dari masing-masing dimensi, dimensi autonomy, dan dimensi positive relationship with others berada pada kategori rendah, sedangkan dimensi environmental mastery, personal growth, purpose in life, dan self- acceptance berada pada kategori sedang. Perbedaan hasil penelitian ini dengan penelitian Kertamuda dan Syamsu (2014) kemungkinan dikarenakan penelitian tersebut dilaksanakan di Bekasi yang merupakan bagian dari kabupaten Jawa Barat sementara penelitian ini dilaksanakan di Jakarta. Perbedaan wilayah dapat menyebabkan peraturan dan kegiatan yang dilaksanakan berbeda, mengingat bahwa PKK diketuai oleh istri gubernur setempat serta kegiatan PKK menyesuaikan dengan kebutuhan masyarakat di daerah setempat.

Penelitian ini konsisten dengan hasil penelitian Machmud dan Putri (2015) yang menemukan kesejahteraan psikologis yang tinggi pada lansia yang mengikuti kegiatan posyandu lansia dengan konsep active ageing, dimana kegiatannya meliputi pemeriksaan kesehatan, bimbingan agama, pengembangan keterampilan dan pengelolaan dana sehat. Penelitian lainnya yang juga konsisten dengan penelitian ini adalah penelitian dari Ho (2015) yang menemukan kesejahteraan psikologis yang tinggi pada individu yang mengikuti kegiatan volunteering.

Skor yang tinggi pada dimensi positive relations with others berarti individu mempunyai hubungan positif yang baik dengan orang lain, peduli terhadap kesejahteraan orang lain, mampu berempati, berafeksi dan membina kedekatan denang orang lain, memahami perlunya memberi dan menerima dalam membina hubungan dalam orang lain. Keterlibatan dalam kegiatan berorganisasi dan volunteering memberikan sarana bagi individu untuk bertemu dengan orang lain dan membina hubungan dan dapat meningkatkan empati (Borgonovi, 2008).

Personal growth ditandai dengan adanya keinginan untuk terus berkembang, keterbukaan terhadap pengalaman yang baru. Pada penelitian ini anggota PKK memperoleh skor tinggi pada dimensi ini. PKK menyediakan berbagai pelatihan bagi kader maupun masyarakat untuk meningkatkan kesejahteraan mereka. Berdasarkan data wawancara, ketiga partisipan mengatakan bahwa banyak ilmu baru yang mereka dapatkan selama aktif di PKK. Ketiga subjek yang diwawancarai juga mengaku bahwa awal mula mereka tertarik mengikuti PKK salahsatu alasannya adalah karena tertarik dengan pelatihan.

Anggota PKK Kelurahan TDU memiliki purpose in life yang tinggi. Hal ini berarti anggota PKK Kelurahan TDU percaya bahwa adanya tujuan yang ingin dicapai dalam hidup, adanya makna dan arah dalam hidupnya (Ryff, 2014). Hal ini dapat dilihat dari aitem nomor enam yaitu "saya memiliki tujuan hidup". Mayoritas partisipan menjawab setuju pada pernyataan ini $(n=47 ; 60 \%)$, serta 24 partisipan $(30 \%$ dari 78 partisipan) menjawab sangat setuju dengan pernyataan ini, dan 4 partisipan (5\%) menjawab agak setuju. Hanya 3 orang menjawab agak tidak setuju, tidak setuju, dan sangat tidak setuju. Anggota PKK Kelurahan TDU merasa yakin bahwa mereka memiliki tujuan hidup. Pada saat partisipan mengisi kuesioner mereka juga mayoritas mengatakan bahwa manusia pasti memiliki tujuan hidup.

Berdasarkan hasil wawancara dengan tiga orang partisipan mengenai dimensi tujuan hidup dan penerimaan diri, semua partisipan memiliki tujuan hidup. Ketiga partisipan menyatakan 
bahwa tujuan hidup mereka adalah mengabdi pada masyarakat. Namun ketiganya menganggap tujuan hidup mereka yang utama adalah keluarga. Setelah keluarga mereka dianggap sejahtera, tujuan hidup mereka adalah menyejahterakan masyarakat. Penelitian dari An dan Cooney (2006) menemukan bahwa adanya pengaruh kualitas generatif kepada kesejahteraan psikologis terutama pada wanita. Kualitas generatif adalah perasaankeharusan untuk menolong orang lain dan masyarakat yang dapat dilakukan melalui volunteering, memberikan kontribusi kepada masyarakat, dan lainlain. Perasaan berkewajiban untuk membantu masyarakat ini merupakan faktor protektif dalam mengurangi depresi (Greenfield, 2009). Dukungan yang diterima dari lingkungan atau masyarakat dapat mempertahankan tingkat kesejahteraan psikologis yang tinggi (Greenfield \& Reyes, 2014; Pinquart dan Sorenson, 2003 dalam Desiningrum, 2010). Hal ini terjadi karena masyarakat sekitar atau tetangga dapat berperan sebagai sumber utama dukungan dan pemaknaan hidup di usia dewasa (Gardner, 2011).

Berdasarkan hasil dari wawancara, partisipan $\mathrm{C}$ dan $\mathrm{T}$ menjelaskan bahwa tujuan hidup mereka adalah untuk mengabdi di masyarakat. Partisipan C dan $T$ sudah berpartisipasi di PKK selama kurang lebih masing-masing 15 dan 30 tahun. Lama mereka berpartisipasi nampaknya membuat tugas dan peran mereka di PKK melekat menjadi tujuan hidup mereka. Berbeda dengan partisipan $G$ yang baru berpartisipasi di PKK selama tiga tahun. $\mathrm{G}$ menyebutkan tujuan hidupnya berdasarkan agama.

Self-acceptance ditandai dengan memiliki sikap positif terhadap diri, mengakui dan menerima berbagai aspek dari diri sendiri termasuk kelebihan maupun kekurangan, merasa positif mengenai masa lalu. Individu yang memiliki penerimaan diri yang rendah merasa tidak puas dengan diri sendiri, kecewa terhadap apa yang terjadi di masa lalu, bermasalah dengan kualitas tertentu dalam dirinya, dan berharap menjadi orang yang berbeda dengan dirinya (Ryff, 2014). Pada aitem dengan dimensi penerimaan diri yaitu "saya menyukai sebagian besar kepribadian saya" terdapat 9\% dari partisipan yang berada pada kategori rendah, $13 \%$ partisipan yang berada pada kategori sedang, dan $78 \%$ berada pada kategoritinggi.

Penerimaan diri pada partisipan wawancara secara umum digambarkan dengan kata ikhlas dan menerima. Partisipan memandang sifat-sifat buruk yang ia punyai sebagai hal yang manusiawi, dan kepribadian sebagai pemberian dari Allah yang harus individu terima. Dari hasil wawancara, selfacceptance yang digambarkan oleh ketiga partisipan lebih mengacu kepada situasi di luar dirinya. Hal ini berbeda dengan Ryff (2014) yang menggambarkan selfacceptance sebagai keadaan di mana individu menerima diri sendiri, segala kelebihan dan kekurangan dalam dirinya, serta memandang masa lalunya dengan positif.

Dalam konteks budaya Timur, penerimaan diri memang dapat diartikan menerima takdir Tuhan dan menerima segala sesuatu yang tidak dapat dirubah (Subandi, 2016). Hasil studi dari Chizanah (2011) mengenai konstruk ikhlas menyatakan ikhlas sebagai konfigurasi dari konsep diri sebagai hamba Allah, motif transendental, harapan untuk mencapai kedekatan dengan Allah, nilai-nilai transendental, penghambaan, serta kebaikan. Hal ini sesuai dengan hasil wawancara dari subjek $\mathrm{G}$ mengenai keikhlasan.

\section{SIMPULAN}

Kesimpulan pada penelitian ini adalah kesejahteraan psikologis perempuan anggota PKK di Kelurahan TDU berada pada kategori tinggi jika dilihat dari total kesejahteraan. Akan 
tetapi jika dilihat dari masing-masing dimensi, dimensi environmental mastery berada pada kategori sedang, sedangkan dimensi lain berada pada kategori tinggi. Berdasarkan data yang didapat dari wawancara dengan tiga orang partisipan, ketiga partisipan tujuan hidup utamanya adalah menyejahterakan keluarga, setelah keluarga dianggap sejahtera maka tujuan selanjutnya adalah mengabdi pada masyarakat. Penerimaan diri digambarkan oleh partisipan dengan kata ikhlas. Implikasinya adalah perempuan di usia dewasa, paruh baya hingga lansia dapat mengikuti kegiatan volunteering agar dapat meningkatkan kesejahteraan psikologisnya. Keterbatasan penelitian ini adalah peneliti hanya mewawancarai partisipan dengan kesejahteraan psikologis yang tinggi.

\section{SARAN}

Peneliti menyarankan peneliti selanjutnya dapat mewawancarai juga partisipan yang memiliki kesejahteraan psikologis rendah. Selain itu, penelitian selanjutnya dapat meneliti kesejahteraan psikologis menggunakan skala yang diadaptasi ke dalam bahasa dan budaya Indonesia sehingga skala lebih dapat dipahami oleh partisipan. Peneliti menyarankan perempuan di usia dewasa, paruh baya hingga lansia dapat mengikuti kegiatan volunteering agar dapat meningkatkan kesejahteraan psikologisnya.

\section{DAFTAR PUSTAKA}

An, J. S., \& Cooney, T. M. (2006). Psychological well-being in mid to late life: The role of generativity development and parent-child relationships across the lifespan. International Journal of Behavioral Development, 30(5), 410-421.

Azwar, S. (2015). Penyusunan skala psikologi. Yogyakarta: Pustaka Pelajar.

Borgonovi, F. (2008). Doing well by doing good. The relationship between formal volunteering and self-reported health and happiness. Social science \& medicine,
66(11), 2321-2334. Chizanah, L. L. (2011). Ikhlas $=$ prososial? Studi komparasi berdasar CAPS. Jurnal Psikologi Islam (JPI) Lembaga Penelitian Pengembangan Psikologi dan Keislaman (LP3K), 8(2), 145-164.

Chizanah, L. L. (2011). Ikhlas= Prososial? Studi komparasi berdasar CAPS. Jurnal Psikologi Islam (JPI) Lembaga Penelitian Pengembangan Psikologi dan Keislaman (LP3K), 8(2), 145-164.

Choi, N. G., \& Kim, J. (2011). The effect of time volunteering and charitable donations in later life on psychological wellbeing. Ageing and Society, 31(04), 590-610.

Creswell, J. W. (2012). Research design:

Qualitative, quantitative, and mixed methods approaches. California: Sage Publication.

Desiningrum, D. R. (2010). Family's social support and psychological well-being of the elderly in Tembalang. Anima, Indonesian Psychological Journal, 26(1), 61-68.

Diener, E. (2000). Subjective well-being the science of happiness and a proposal for national index. American Psychologist Vol. 55 No. 1, 34-43.

Diener, E., Oishi, S., \& Lucas, R. E. (2003). Personality, culture, and subjective well-being: Emotional and cognitive evaluations of life. Annual review of psychology, 54(1), 403- 425.

Gardner, P. J. (2011). Natural neighborhood networks-Important social networks in the lives of older adults aging in place. Journal of Aging Studies, 25(3), 263-271.

Greenfield, E. A., \& Marks, N. F. (2004). Formal volunteering as a protective factor for older adults' psychological well-being. The Journals of Gerontology Series B: Psychological Sciences and Social Sciences, 59(5), S258-S264.

Greenfield, E. A. (2009). Felt obligation to help others as a protective factor against losses in psychological well-being following functional decline in middle and later life. The Journals of Gerontology Series B: Psychological Sciences and Social Sciences, 64(6), 723-732.

Greenfield, E. A., \& Reyes, L. (2014). Continuity and change in relationships 
with neighbors: Implications for psychological well-being in middle and later life. The Journals of Gerontology Series B: Psychological Sciences and Social Sciences, 70(4), 607-618.

Ho, H. C. (2015). Elderly volunteering and psychological well-being. International Social Work, 1(11), 1-11.

Kertamuda, F., \& Syamsu, L. (2014). Psychological well-being of mothers who are members of the movement empowerment and family welfare: A preliminary study. Research on Humanities and Social Sciences, 4(6), 100-103.

Machmud, R., \& Putri, K. S. (2015). Analisis karakteristik keluarga dan pemanfaatan posyandu lansia terhadap psychological well being lansia di Kecamatan IV Angkek Kabupaten Agam tahun 2014. Jurnal Kesehatan Andalas, 4(1), 122-129.

Nezlek, J. B., \& Allen, M. R. (2006). Social support as a moderator of day- to- day relationships between daily negative events and daily psychological wellbeing. European Journal of Personality, 20(1), 53-68.

Poerwandari, E. K. (2013). Pendekatan kualitatif untuk penelitian perilaku manusia. Jakarta: Fakultas Psikologi Universitas Indonesia.

Purnomo, A., \& Hadiwirawan, O. (2017). Kesejahteraan Subjektif Anggota PKK di Jakarta. Skripsi (tidak diterbitkan). Jakarta: Fakultas Psikologi UKRIDA.

Rantung, J., \& Mandey, J. (2014). Peranan pemberdayaan kesejahteraan keluarga (PKK) dalam menggerakkan partisipasi masyarakat desa (suatu studi di Desa Ongkau I Kabupaten Minahasa Selatan. Jurnal Administrasi Publik, 4(5), 1-11.

Ruini, C., \& Ryff, C. D. (2016). Using eudaimonic well-being to improve lives. In Wood, A. M., \& Johnson, J. (Eds.), The Wiley Handbook of Positive Clinical Psychology (pp. 153-166). New Jersey: John Wiley \& Sons.

Ryff, C. D., \& Keyes, C. L. M. (1995). The structure of psychological well-being revisited. Journal of personality and social psychology, 69(4), 719.

Ryff, C. D. (2013). Psychological well-being revisited: Advances in the science and practice of eudaimonia. Psychotherapy and psychosomatics, 83(1), 10-28.

Ryff, C. D. (2013b). Psychological well-being revisited: Advances in the science and practice of eudaimonia. Psychotherapy and psychosomatics, 83(1), 10-28.

Ryff, C. D. (2014). Psychological well-being revisited: Advances in the science and practice of eudaimonia. Psychotherapy and psychosomatics, 83(1), 10-28.

Son, J., \& Wilson, J. (2012). Volunteer work and hedonic, eudaimonic, and social well- being. Sociological Forum, 27(3), 658-681.

Subandi, M. A. (2011). Sabar: Sebuah konsep psikologi. Jurnal Psikologi, 38(2), 215227.

Žižek, S. Š., Treven, S., \& Čančer, V. (2015). Employees in Slovenia and their psychological well-being based on Ryff's model of psychological wellbeing. Social Indicators Research, 121(2), 483-502. 